\title{
The Effect of Group Counselling Based on the Modification of Negative Self-Statements on Reducing Gender-Biased Foreign Language Anxiety among Ajloun National University Students
}

\author{
Mohammad H. Abood* \& Nadia Ahouari-idri \\ Hashemite University, Jordan University of Bejaia, Algeria \\ Received: 13/11/2016_ Accepted: 12/2/2017
}

\begin{abstract}
This study investigated the effectiveness of a training program, based on the modification of negative self-statement, to reduce foreign language anxiety (FLA) among EFL students at university in Jordan. To achieve this goal, the foreign language classroom anxiety scale was used. Participants were 30 male and female students from Ajloun National University, who scored high in FLA, and randomly dispensed to one of the two groups: experimental and control. The experimental group received a pilot programme to modify the negative self-statement and the control group did not. Results showed that the modification of negative self-statement program (MNSP) was effective in reducing FLA. A statistically significant difference (.05) was found between the two groups in the effectiveness of the self-statement programme.
\end{abstract}

Keywords: Foreign language, foreign language anxiety, negative self-statement, negative self-statement programme.

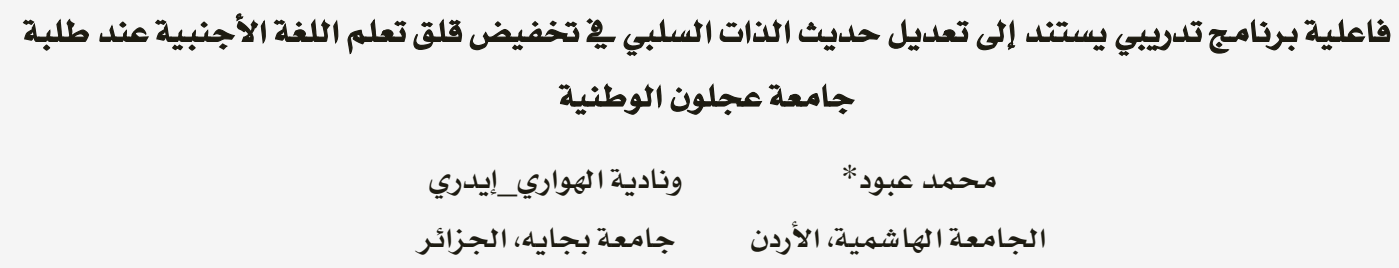

مستخلص: هدفت هذه الدراسة إلى استقصاء فاعلية برنامج تدريبي يستتد إلى تعديل حديث الذات السلبي ِِّْ تخفيض قلق تعلم اللفة الأجنبية عند طلبة الجامعة من مرحلة البكالوريوس، ولتحقيق أهداف الدراسة تم استخدام مقياس قلق اللغة الأجنبية. تكونت عينة التهاه

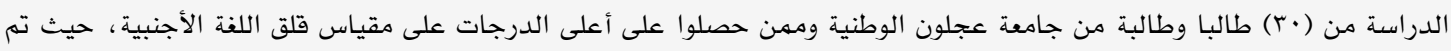

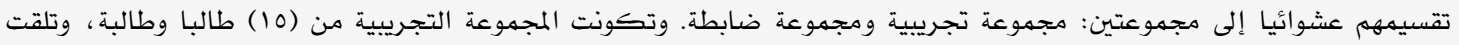

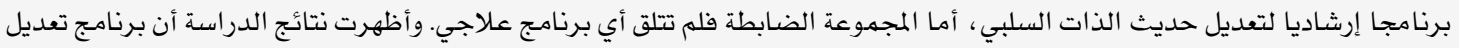

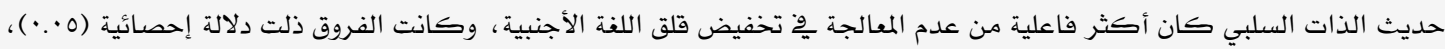
وأظهرت النتائج وجود فروق ذات دلالة إحصائية (0.. ) مِّ فاعلية برنامج تعديل حديث الذات السلبي حسب الجنس ولصالح الذكور. الكلمات المفاتحية: اللغة الأجنبية، قلق اللفة الأجنبية، حديث الذات السلبي، برنامج تعديل حديث الذات السلبي. 
The term anxiety is not specific to language learning. In clinical psychology, when considered as a severe illness, it is called generalized anxiety disorder (GAD). In clinical psychology, anxiety is translated into its symptoms. In this paper, the authors regard FLA as an affective variable; i.e. as a psycho-physiological phenomenon explained by inherent and apparent features.

In foreign language learning (FLL), affective factors have been studied since the 1970 by several researchers (e.g., Aida, 1994; GarciaMarques \& Loureiro, 2016; Horwitz, Horwitz \& Cope, 1986; Wright, Hopwood \& Simms, 2015; Yamashita, 2015). Among the affective variables, anxiety is a main blocking factor for effective language learning (Sultan, 2012; Tanielian, 2014). Anxiety has been treated differently by scholars, whether as a cause of learning (Mejía, 2014), or a consequence of learning (Liao \& Wang, 2015; Mejía, 2014; Sul$\tan , 2012)$. Anxiety is a highly influential factor in foreign language teaching and learning contexts. It is indeed to such a context that researchers defend the thesis that FLA is debilitating and focus on how to cope with it for better learning.

Being aware of the damaging effects of negative affect that stem from the inherent feelings in the individual, debilitating anxiety can be caused by negative self-statements. Students can go through internal speech related to learning the foreign language and negatively self-evaluate themselves or their performance. Self-evaluation has been focused of researchers since the 1960s' because it contributes to effective and active learning (Idri, 2014). However, in case self-evaluations are negative, learners often become apprehensive toward the foreign language when their beliefs are negative toward themselves. In relation to FLA, Horwitz et al. (1986) defined it as "a distinct complex of self-perception, beliefs feelings and behaviors related to classroom language learning arising from the uniqueness of the language learning process" (p. 125). Hence, when foreign language learners perceive themselves negatively and feel bad about themselves, anxiety can be high. When learners, then, feel bad towards themselves, their negative self-statements are more likely to develop leading to further anxiety. As an efficient technique to help learners overcome anxiety, the authors suggested a counseling technique based on the modification of negative self-statements.

Several researchers (e.g., Al-Khasawneh, 2016; Garcia-Marques \& Loureiro, 2016; Liao \& Wang, 2015; Mejía, 2014; Mohammed, 2015; Sultan, 2012; Tanielian, 2014; Yamashita, 2015) mentioned that anxiety is one of the affective variables that influences teaching and learning in different individuals and contexts. Horwitz et al. (1986) claimed that anxiety specific to FLL exists and it is associated with the three concepts: communication apprehension, fear of negative evaluation, and test anxiety. To treat these varieties, the Foreign Language Classroom Anxiety Scale (FLCAS) was developed to frame the anxiety response to a foreign language situation on the one hand, and to measure the three performance anxieties on the other. Horwitz et al. (1986) found that there was a significant correlation between anxiety and its varieties. Foreign Language Anxiety showed its effect on other learning variables like grades (Idri, 2012) and performance (Tanielian, 2014).

Research has always tried to discover the relationship between anxiety and other variables. In addition, many trials are in progress to find ways out to reduce this phenomenon in language classes (Deb, 2016; Liao \& Wang; Tanielian, 2014; Martirossian1 and Hartoonian, 2015). However, few attempted to test the effectiveness of a treatment programme to help foreign language learners cope with it. As an attempt to find an effective programme, this study comes to test the effectiveness of one of the counseling programmes that cope with FLA; the Modification of Negative SelfStatement Programme (MNSP). Such a Programme is one of the methods of psychological therapy that is based on teaching individuals how to replace negative self-thoughts with positive ones throughout a 10 sessions' psychological proramme. Experimental studies that try to test the effectiveness of modifying negative self-statements in reducing FLA are occasional. Yet, they are needed to be part of the FLL training in order to accompany students who suffer from FLA. The tested programme was applied in a FLL context with university students at Ajloun National University, Jordan. The present study attempts to test the following hypotheses: 
1. There are statistically significant differences in favour of the experimental group in treating FLA compared to the control group.

2. There are statistically significant differences due to gender in the experimental group's performance in the treatment of FLA.

\section{Method}

The study at hand used an experimental design based on two groups; one experimental and one control containing 15 students each. The adopted counselling programme is the independent variable of the research. It was applied as a treatment to the experimental group in order to test its role in reducing FLA among students. Hence, both groups were subjected to pre- and post-test measurements to compare the results. This makes the employed method purely quantitative.

\section{Participants}

The sample of the study consists of 30 students who had high scores on the foreign language classroom anxiety scale (FLCAS), and agreed to participate in the study. Participants were divided into two groups, an experimental group and a control group of 15 students each. Members of the experimental group were trained on adjusting negative self-statements whereas members of the control group were not subjected to this treatment. The overall number of students at Ajloun National University is 1550 male and female bachelor students who study during the first semester of the academic year 2014-2015.

\section{Instruments}

The Foreign Language Anxiety Scale (FLCAS). The authors first used Hortwiz, Horwitz and Cope's FLCAS which consists of 33 items based on a five Likert-type scale: 0 : strongly disagree to 5: strongly agree. The lowest score on the scale can be 0 and the highest can be 165 . The scale was translated from English into Arabic. Both versions were reviewed by specialists in educational psychology, counselling and English. They were required to review the items in terms of language style and clarity of the meaning for each item. Based on their feedback, modifications related to a number of items were applied.

In terms of reliability, Horwitz et al.'s (1986, p. 129) FLCAS proved to be a reliable instru- ment. It achieved an alpha coefficient of 0.93 . In terms of the scale's validity, many researchers (e.g., Aida, 1994; Gi-Pyo Park, 2014; Horwitz, 2016) found the scale valid in their studies. As concerns its reliability in the present study, the Cronbach's alpha reliability coefficient was 0.82 .

\section{Modification of Negative Self-statements Programme: Description and Procedure}

The authors applied the MNSP on the experimental group via 12 treatment sessions; three sessions per week (the programme is considered valid at the level of ten sessions and more). Each session lasted 50 minutes. The sessions aimed at helping students suffering from FLA to get rid of the negative self-talk that leads to anxiety, and substitute it with a more positive talk that stimulates the self in foreign language contexts.

\section{The Description of the Sessions}

Session 1. This session is introductory to let the counsellor and the members of the group know each other. The session aims also at introducing the collective counselling technique, presenting the programme objectives, delimiting the standards of group work and identifying the members' expectations and receiving the members' approval to take part in the programme.

Session 2. This session aims to define the concept of foreign language anxiety (FLA), its causes, its effects and how to cope with it.

Session 3. The aim of this session is to adjust the first negative self-statement, show that it is illogical and substitute it with a more logical expression: "It is impossible to master the foreign language."

Session 4. The aim of this session is to adjust the second negative self-statement, show that it is illogical and substitute it with a more logical expression: "I feel embarrassed and confused when I make errors in the foreign language in front of others."

Session 5. The aim of this session is to adjust the third negative self-statement, show that it is illogical and substitute it with a more logical expression: "This age is not suited me to learn the foreign language."

Session 6. The aim of this session is to adjust the fourth negative self-statement, show that it is illogical and substitute it with a more logical 
expression: "I do not need to learn the foreign language."

Session 7. The aim of this session is to adjust the fifth negative self-statement, show that it is illogical and substitute it with a more logical expression: "I extremely dislike the foreign language."

Session 8. The aim of this session is to adjust the sixth negative self-statement, show that it is illogical and substitute it with a more logical expression: "Learning a foreign language needs many years of study."

Session 9. The aim of this session is to adjust the seventh negative self-statement, show that it is illogical and substitute it with a more logical expression: "I should be very careful because I feel afraid of making errors when speaking the foreign language."

Session 10. The aim of this session is to adjust the eighth negative self-statement, show that it is illogical and substitute it with a more logical expression: "I feel angry when I find that others learn the foreign language better than me."

Session 11. The aim of this session is to adjust the ninth negative self-statement, show that it is illogical and substitute it with a more logical expression: "Learning a foreign language needs a level of intelligence."

Session 12. This is the final session. Its aim is to review what was done in the programme, connect between the sessions, identify the members' reactions towards the programme and finally thank the members of their commitments in attending the sessions. The researcher also ended the session by urging the members for a future follow up in case of need or advice.

\section{Procedure}

At the beginning, the scale was administered to experts after its translation. Then, it was piloted to check its consistency. The scale was, then, administered to the research sample. According to the scale's results, authors could select the students who got the highest levels of FLA, who volunteered to take part in the study. The control group was subject of treatment and participated in the collective treatment programme to reduce FLA. The programme was made up of twelve sessions and lasted four weeks. The first researcher played the role of the counsellor. At the end of the last session, post-test measurement was processed.

\section{Results}

To test the two hypotheses of the study, the following statistical procedures were used:

- Calculation of means and standard deviations of the FLCAS levels among the members.

- Independent samples: T-test was used in order to find out the difference in FLA attributed to group and gender.

Table 1 shows results of the pre-test. Means and standard deviations are indicated for both groups. In addition, a t-test was used as an independent test to indicate statistical differences between the means.

Table 1

Mean, Standard Deviations and t- test of Pre-

\begin{tabular}{lrrrrrr}
\multicolumn{7}{c}{ test FLA by Group } \\
\hline Group & $\mathrm{N}$ & $\mathrm{M}$ & $\mathrm{SD}$ & $\begin{array}{c}\mathrm{t}- \\
\text { Value }\end{array}$ & df & $\mathrm{p}$ \\
\hline Experimental & 15 & 3.67 & .430 & & & \\
Control & 15 & 3.72 & .387 & & &
\end{tabular}

Table 1 shows no statistical significance (0.05) for the group variable (experimental/control) where the t-test value was -.284 with .778 of statistical significance. This result shows equivalence between the groups.

Hypothesis 1: There are statistically significant differences (0.05) in favour of the experimental group to treat FLA compared to the control group. To test the hypothesis, means and standard deviations for both groups; experimental and control, for post-test FLA were calculated. In order to find out the statistical differences between the mean scores, a $t$-test was used. Results are displayed in Table 2:

Table 2

Means, Standard Deviations and t-test of Post-test Group

\begin{tabular}{rcccccc}
\hline \multicolumn{8}{c}{ Group } \\
Group & N & M & SD & $\begin{array}{c}\text { t- } \\
\text { value }\end{array}$ & df & p. \\
\hline $\begin{array}{r}\text { Experimental } \\
\text { Control }\end{array}$ & 15 & 2.93 & .314 & -3.706 & 28 & .001 \\
\hline
\end{tabular}

Table 2 shows no statistical significance (0.05) for the group variable (experimental/control) where $\mathrm{t}$-test value was -3.706 with $\cdot .001$ statistical significance.

Hypothesis 2: There are statistically significant differences (0.05) for gender in favour of 
the experimental group to treat FLA compared to the control group.

To test the hypothesis, mean scores and standard deviations for post-test FLA according to sex were calculated. In order to find out the statistical differences between mean scores, a t-test was used. Results are displayed in Table 3:

Table 3

Means, Standard Deviations and t-tests of FLA Post-test by Gender

\begin{tabular}{crccccc}
\multicolumn{7}{c}{ Post-test by Gender } \\
\hline Group & N & M & SD & t-Value & df & p \\
\hline Male & 8 & 2.75 & .330 & \multirow{2}{*}{-2.728} & \multirow{2}{*}{13} & \multirow{2}{*}{017} \\
Female & 9 & 3.12 & .140 & & &
\end{tabular}

\section{Discussion}

Results showed that there exists a statistical variance between the experimental group and the control group. This indicated that reducing FLA $t$ was more efficient with the selfadjustment programme than not using it among students. This shows that the first hypothesis related to the group variable is verified. This can explain the efficiency of using the counselling programme to reduce FLA among university student. Hence, FLA can be treated by adopting the Programme since it plays a role in the individual's motivation and self-confidence.

Self-talk plays a major role in one's thoughts, emotions and behaviours. Hence, when dealing with negative self-talk and working on them, discussing them and trying to transform them into positive thoughts, the individual is more likely to have a more positive self-image and sees the Self in stigmatic shape. This leads the individual to gain more selfconfidence in himself and improve his willingness to learn the foreign language and, eventually, work on diminishing the degree of fear and apprehension. On the other hand, the individual with negative self-statements perceives himself negatively and feels apprehension when learning a foreign language and, thus, affects the way he learns it negatively. In this, the anxiety felt in such a situation is debilitating to the learning enterprise. That is why counselling programmes can be efficient to lower the level of FLA through the modification of negative self-statements learners hold in FLA. Such programmes are important as they offer counselling services to learners who suffer from FLA and this is in order to improve the positive self-statements in them. This is because negative self-statements are a predictor of anxiety (Kendall \& Treadwell, 1996).

This hypothesis results indicated there exists a statistical variance between male and female in terms of self-talk. Males use more self-talk compared to females. In this, females are more likely to seek other communicative channels to express what they suffer from in relation to negative feelings and thoughts vis-à-vis the external world and without refuge to repression or ongoing self-talk. However, males resort to self-talk and think of the situations they face deliberately. Hence, males choose self-talk more often compared to females. This characteristic lead them adopt negative self-talks from which the foreign language learning situation is part of. That is why the MNSP as a supportive way to students in order to modify the negative thoughts they might have adopted towards learning the foreign language. Such male students' interaction opportunities with the programme was higher compared to female students.

\section{Implications and Suggestions}

In the light of the findings the authors reached, they recommend:

- Employ the modification of negative selfstatement programme to treat students who suffer from FLA as shown through the results of the present study about the efficiency of this programme.

- Conduct further studies to experience the efficiency of other counselling programmes that aim at treating FLA in students.

- Organize regular training sessions and workshops to education counsellors and educational psychologists in order to cope with FLA when cases appear in educational settings.

- Replicate the experiment with a larger sample, in different contexts, with different age groups and at different educational levels. This will more likely permit to generalize the MNSP programme and adjust it to the context where it needs be applied. 


\section{References}

Aida, Y. (1994). Examination of Horwitz, Horwitz, and Cope's construct of foreign language anxiety: The case of students of Japanese. Modern Language Journal N. 78, vol. 2, 155-168. Arnold, J. (1999). Affect in Language Learning. Cambridge: Cambridge Language Teaching: Cambridge University Press.

Al-Khasawneh, F. M. (2016). Investigating foreign language learning anxiety: a case of Saudi undergraduate EFL learners. Journal of Language and Linguistic Studies, 12(1), 137148.

Deb, P. K. (2016). Comics as a Means of Humor and Minimizing Classroom ty. IUP Journal of English Studies 11(1), 6669.

Garcia-Marques, T. \& Loureiro, F. (2016). Dispositional beliefs regarding "affect as information" determine the perception of persuasive self-efficacy. Análise Psicológica, 1 (XXXIV), 73-86

Gi-Pyo, P. (2014). Factor analysis of the foreign Language classroom Anxiety Scale in korean Learners of English as a Foreign language. Psychological Reports. 115, 261-275.

Horwitz, E. K. (2016), Reflections on Horwitz (1986), "Preliminary Evidence for the Validity and Reliability of a Foreign Language Anxiety Scale". TESOL Quarterly. doi: $10.1002 /$ tesq.295

Horwitz, E. K., Horwitz, M. B., \& Cope, J. (1986). Foreign Language Classroom Anxiety. The Modern Language Journal, 70, 125132.

Idri, N. (2012). Foreign language anxiety among Algerian EFL students: The case of first year students of English at the university of Abderahmane Mira-Bejaia; LMD (Licence/Master/Doctorat) system group. Universal Journal of Education and General Studies, 1(3), 55-064.

Idri, N. (2014). Fear of Negative Evaluation as a Variety of Anxiety in Foreign Language Learning. A Doctoral Dissertation Submitted to get a Doctoral Degree in Didactics of English. University of Constantine 1.
Kendall, R. H., \& Treadwell, P.C. (1996). Selftalk in youth with anxiety disorders: States of mind, content specificity, and treatment outcome. Journal of Consulting and Clinical Psychology, 64, 941-950.

Liao, H. C. \& Wang, Y. H. (2015). Creating a positive Learning Environment for students with English Classroom Anxiety. Psychological Reports: Sociocultural Issues in Psychology, 116( 2). 631-646.

Martirossian, A. \& Hartoonian, A. (2015). Lowering Foreign Language Anxiety through Self-Regulated Learning Strategy Use. English Language Teaching, 8(12).

Mejía, G. (2014). A Case Study of Anxiety in the Spanish Classroom in Australia, Journal of University Teaching $\mathcal{E}$ Learning Practice, 11(3).

Mohammed, A. (2015). EFL Effective Factors: Anxiety and Motivation and their Effect on Saudi College Student's Achievement. Arab World English Journal (AWEJ) 6(2). 201 - 218

Sultan, S. (2012). Students' Perceived Competence Affecting Level of Anxiety in Learning English as a Foreign Language Sarwat. Pakistan Journal of Psychological Research, 27(2). 225-239.

Tanielian, A. R. (2014). Foreign language anxiety in a new English program in Thailand. The International Education Journal: Comparative Perspectives, 13(1). 60-82.

Wright, A. G., Hopwood, C. J., \& Simms, L. J. (2015). Daily interpersonal and affective dynamics in personality disorder. Journal of personality disorders, 29(4), 503. 